\title{
The change of a district hospital antimicrobial consumption in and after national antimicrobial appropriate use intervention, China
}

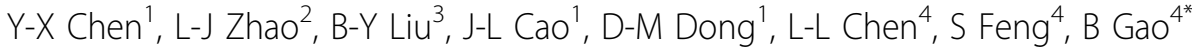 \\ From 3rd International Conference on Prevention and Infection Control (ICPIC 2015) \\ Geneva, Switzerland. 16-19 June 2015
}

\section{Introduction}

Clinical use of antimicrobial was promoted by a national special clinical antimicrobial appropriate use program (2011 2013) and legislation (in 2012) by the Ministry of Health in China.

\section{Objectives}

To investigate the time-phased effectiveness of the national intervention to antimicrobial clinical use in a district hospital, China.

\section{Methods}

Multi-strategy according to national special program and legislation to reasonable use of antimicrobial, including antimicrobial prescribe target setting, surveillance on prophylactic use of antimicrobial rate to clean wound surgery and surgical set infection, and, as well as performance feedback etc, were introduced in a district hospital since 2011. WHO Anatomical Therapeutic Chemical classifications of antimicrobial was used in calculated defined daily doses (DDDs). Annual antimicrobial consumption data from 2011.1 to 2014.12 were obtained and converted to DDDs per 1,000 patient-days.

\section{Results}

The strength of antimicrobial consumption by DDDs per 1,000 patient-days was decreased in the hospital by $32.20 \%, 1745.940,1143.471,1144.949$, and 1183.821 , respectively from 2011 to 2014 . About $70 \%$ of antimicrobials use was stably prescribed in its outpatient settings during the investigation (73.32\% in $2011,70.74 \%$ in 2012 , $68.39 \%$ in 2013 , and $68.47 \%$ in 2014). The strength of antimicrobial consumption by DDDs per 1,000 patientdays was decreased by $70.32 \%$ in the inpatient-units performing surgical procedure with clean wound, 623.819, $337.267,276.622$ and 224.563, respectively from 2011, meanwhile decreasing prophylactic use to class one wound, $42.28 \%(416 / 984$ in 2011), $21.95 \%(373 / 1699$ in 2012), $14.77 \%(288 / 1950$ in 2013) and $14.24 \%(232 / 1629$ in 2014). During the same time, the strength of antimicrobial consumption by DDDs per 1,000 patient-days was increased by $22.30 \%$ in the rest inpatient-units, 383.947 , $332.685,418.225$ and 467.484 , respectively.

\section{Conclusion}

National intervention of antimicrobial judicious use was effective in outpatient clinic and units operating clean procedure in the district hospital.

\section{Disclosure of interest}

None declared.

\section{Authors' details}

'Nosocomial Infection Control Unit, Wuqing District Hospital, China. ${ }^{2}$ Pharmacy, Wuqing District Hospital, China. ${ }^{3}$ Clinical Microbiologic lab, Wuqing District Hospital, China. ${ }^{4}$ Faculty of Graduate Research, Tianjin Medical University, Tianjin, China.

Published: 16 June 2015

doi:10.1186/2047-2994-4-S1-P179

Cite this article as: Chen et al:: The change of a district hospital antimicrobial consumption in and after national antimicrobial appropriate use intervention, China. Antimicrobial Resistance and Infection Control 2015 4(Suppl 1):P179.

${ }^{4}$ Faculty of Graduate Research, Tianjin Medical University, Tianjin, China Full list of author information is available at the end of the article 